\title{
Effects of Laser Irradiation on a Copper Electrodeposition Process and Coating Quality
}

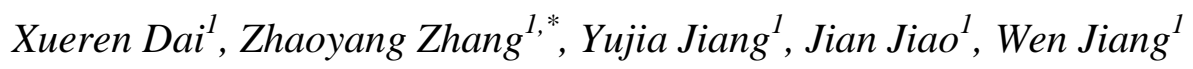 \\ Department of Mechanical Engineering, Jiangsu University, Zhenjiang 212013, China \\ *E-mail: zzhaoyang@126.com \\ doi: $10.20964 / 2017.10 .73$
}

Received: 29 June 2017 / Accepted: 12 August 2017 / Published: 12 September 2017

\begin{abstract}
In this study, a hybrid pulsed laser and electrochemical processing technique was used to deposit a copper coating on a stainless steel substrate. The laser irradiation mechanism in the electrodeposition process was studied by detecting the mechanical and thermal effects. The electrodeposition samples were irradiated by lasers with varying single-pulsed energies and compared. The grains of the coating were observed with a scanning electron microscope (SEM), and the tensile strength and ductility were measured using a UTM4000 series electronic universal testing machine. The results showed that the deposition rate may be increased, and the coating quality may be improved by laser irradiation with the proper single-pulsed energy. This is due to an increase in the conductivity and diffusion coefficient of the solution, arising from an increase in the solution temperature and the local stirring induced by plasma bubbles. The grain size and growth direction of the dendrite are also affected by laser irradiation.
\end{abstract}

Keywords: Pulsed laser; Electrodeposition; Deposition rate; Coating quality; Plasma shockwave

\section{FULL TEXT}

(C) 2017 The Authors. Published by ESG (www.electrochemsci.org). This article is an open access article distributed under the terms and conditions of the Creative Commons Attribution license (http://creativecommons.org/licenses/by/4.0/). 